\title{
əEnvironmental Conditions Associated with Horizontal Convective Rolls, Cellular Convection, and No Organized Circulations
}

\author{
Sean R. Santellanes, ${ }^{\mathrm{a}}$ George S. Young, ${ }^{\mathrm{a}}$ David J. Stensrud, ${ }^{\mathrm{a}}$ Matthew R. Kumjian, ${ }^{\mathrm{a}}$ And Ying Pan ${ }^{\mathrm{a}}$ \\ ${ }^{a}$ Department of Meteorology and Atmospheric Science, The Pennsylvania State University, University Park, Pennsylvania
}

(Manuscript received 25 June 2020, in final form 5 February 2021)

\begin{abstract}
Typical environmental conditions associated with horizontal convective rolls (HCRs) and cellular convection have been known for over 50 years. Yet our ability to predict whether HCRs, cellular convection, or no discernable organized (null) circulation will occur within a well-mixed convective boundary layer based upon easily observed environmental variables has been limited. Herein, a large database of 50 cases each of HCR, cellular convection, and null events is created that includes observations of mean boundary layer wind and wind shear, boundary layer depth; surface observations of wind, temperature, and relative humidity; and estimates of surface sensible heat flux. Results from a multiclass linear discriminant analysis applied to these data indicate that environmental conditions can be useful in predicting whether HCRs, cellular convection, or no circulation occurs, with the analysis identifying the correct circulation type on $72 \%$ of the case days. This result is slightly better than using a mean convective boundary layer (CBL) wind speed of $6 \mathrm{~m} \mathrm{~s}^{-1}$ to discriminate between HCRs and cells. However, the mean CBL wind speed has no ability to further separate out cases with no CBL circulation. The key environmental variables suggested by the discriminant analysis are mean sensible heat flux, friction velocity, and the Obukhov length.
\end{abstract}

SIGNIFICANCE STATEMENT: We spend our lives in the boundary layer, the layer of the atmosphere that extends upward from the ground to a typical daytime depth of $1 \mathrm{~km}$. When viewed from above, there are two common flow patterns that occur within this layer-long parallel lines of rising motion that extend from tens to hundreds of kilometers, with long parallel lines of sinking motion in between, and more circular regions of vertical motion that form adjacent to one another. These flow patterns influence the movement of heat, moisture, and winds within the boundary layer. This study shows that the flow pattern can be predicted from routinely available Doppler radar and surface weather station observations.

KEYWORDS: Boundary layer; Radars/Radar observations; Surface observations; Statistical techniques

\section{Introduction}

Horizontal convective rolls (HCRs) and cellular convection (cells) have been a topic of study since Woodcock (1940) explored the flight patterns of herring gulls in the cold season off the coast of Massachusetts. He observed two distinct flight patterns that were used to deduce very different boundary layer circulation types: a columnar form of ascending motion (cells) and a linear form of ascending motion (HCRs). He found that there was a $10-\mathrm{m}$ wind speed threshold of $7 \mathrm{~m} \mathrm{~s}^{-1}$ at which cells ended and HCRs began, and further suggested that HCRs were not produced for wind speeds $\geq 13 \mathrm{~m} \mathrm{~s}^{-1}$ or when the water temperature was less than the air temperature (suggesting a stable boundary layer). Deardorff (1976) arrived at the same conclusion as Woodcock (1940) using freeconvection scaling arguments. Deardorff suggested that the $13 \mathrm{~m} \mathrm{~s}^{-1}$ limit on HCRs could have been a behavioral choice of herring gulls rather than a wind speed limit of the HCRs themselves.

\footnotetext{
D Denotes content that is immediately available upon publication as open access.
}

Corresponding author: Dr. David J. Stensrud, david.stensrud@ psu.edu
The advent of aircraft, satellite, and radar opened a new era of research on HCRs and cells, as expansive cloud patterns not clearly discernable from the ground became very apparent when viewed from above (Kuettner 1959, 1971; Malkus and Riehl 1964) or via ground-based remote sensing (Angell et al. 1968; Konrad 1970; Berger and Doviak 1978). Kelly (1982) used Doppler radar to investigate the relationship between radar return signals and precipitating HCRs in the Great Lakes region during winter. Doppler radial velocities produced horizontally and vertically alternating confluence and difluence patterns indicative of HCR updraft and downdraft circulations. Doppler radar also was shown to be capable of sensing HCRs in clear air during the warm season owing to an increased concentration of insects within the upward branch of an HCR circulation (Christian and Wakimoto 1989; Geerts and Miao 2005). The ability of Doppler radar to detect HCRs and cells in clear air enhanced our abilities to explore these circulations, because the formation of clouds was no longer needed for detection.

These studies and others led to a basic understanding that in daytime convective boundary layers with moderate surface buoyancy flux, HCRs and cells often develop to help transport heat, moisture and momentum vertically throughout the boundary layer (see Asai 1970; Brown 1980; Atkinson and Zhang 1996 and references therein). When surface buoyancy flux is the driving force, these vertical circulations are hampered by vertical wind 
shear aligned perpendicular to the axis of the vertical circulations. Thus, for larger values of wind shear the axes of the boundary layer vertical circulations tend to be aligned with the wind shear vector and yield the long, linear updraft and downdraft structures characteristic of HCRs. Wind shear is always present in the convective boundary layer owing to the effects of surface friction, and when the wind direction is constant with height the wind shear vector and wind vector are parallel to each other. When this happens, the mean boundary layer wind speed is often a reasonable proxy for the low-level boundary layer wind shear magnitude. However, horizontal temperature and pressure gradients can create boundary layer winds that change direction with height and in these cases the boundary layer wind speed is no longer a good proxy for the low-level boundary layer wind shear magnitude. For smaller values of wind shear the buoyancy effects can dominate over the effects of wind shear yielding no preferred orientation to the updraft and downdraft circulations. Thus, cells become the favored outcome.

Special observations from field experiments also have been critical to improving our understanding of HCRs and cells (e.g., LeMone 1973; Brümmer et al. 1985; Kristovich 1993; Brümmer 1999) as well as their importance to convective initiation, especially near boundaries (Wilson et al. 1992; Xue and Martin 2006; Weckwerth and Parsons 2006). Weckwerth et al. (1997) used a combination of airborne radar and flux measurements to investigate the environmental characteristics that support HCR and cell formation. Their results suggest that moderate sensible heat flux (SHF), some wind shear, and mean convective boundary layer (CBL) wind speeds $\geq 5.5 \mathrm{~m} \mathrm{~s}^{-1}$ were necessary for HCR existence. This wind speed threshold agrees reasonably well with the $7 \mathrm{~m} \mathrm{~s}^{-1}$ threshold found by Woodcock (1940). Below this wind speed threshold value, Weckwerth et al. (1997) show that either cells or no organized boundary layer circulations (nulls) were found.

One of the challenges with using data from field experiments is that, whereas the number of types of available observations is large and the atmospheric sampling is comprehensive, the number of cases for which these observations are available is relatively small. One must turn to operational datasets to obtain a large number of cases. Thankfully, a number of methods are available that provide information on the environmental conditions within CBLs. The velocity-azimuth display (VAD) method can be used to calculate the mean horizontal wind using Doppler radar radial velocity observations at a fixed range gate (Browning and Wexler 1968). Applying the VAD to radial velocity observations at different range gates yields a vertical wind profile from approximately $200 \mathrm{~m}$ above ground level to above the top of the CBL on most days. The addition of dual-polarization observations to the WSR-88D allows layers of Bragg scattering to be identified, which often occurs near the top of the CBL and is characterized by $Z_{\mathrm{DR}}$ values close to $0 \mathrm{~dB}$ (Melnikov et al. 2011, 2013; Davison et al. 2013; Richardson et al. 2017a,b). Banghoff et al. (2018) further showed that the top of the CBL $Z_{i}$ can be estimated from quasi-vertical profiles (QVPs) of differential reflectivity $Z_{\mathrm{DR}}$. Using the estimated $Z_{i}$ and the VAD-derived vertical wind profile one can easily calculate mean CBL wind speed and mean CBL wind shear.
Surface mesonetworks have expanded greatly since 2000 (Mahmood et al. 2017) and some have sufficiently accurate temperature and wind measurements at two heights to provide estimates of SHF and friction velocity $u_{*}$ (Brotzge and Crawford 2000). Thus, using observations from the national network of WSR-88Ds and selected surface mesonets, one can routinely estimate the mean CBL wind speed, mean CBL wind shear, $Z_{i}$, surface virtual potential temperature $\theta_{v}$, surface SHF, and $u_{*}$. These variables can be combined to calculate numerous other helpful boundary layer parameters.

Banghoff et al. (2020) used observations from the Twin Lakes, Oklahoma, WSR-88D over 10 warm seasons (1 April30 September) to document over 1380 cases of HCR and cell occurrence, duration, and associated aspect ratios. They found that on precipitation-free days, HCRs occurred on $71 \%$ of the days, cells occurred on $21 \%$ of the days, and nulls occurred on $7 \%$ of the days. HCRs and cells typically formed in midmorning and persisted on average for 3-4 h. Different circulation types tended to be more common at different times of the warm season, with HCRs being more common in April, May, June, and early July and cells being more common in August and September. Nulls are scattered throughout the warm season. The monthly trends indicate that changing environmental conditions correlate to changes in circulation type, suggesting that environmental conditions can be used to predict circulation type. The Banghoff et al. (2020) study represents the largest dataset of HCRs and cells ever investigated and is the foundation for the present study (dataset available from Stensrud et al. 2019).

Improved knowledge of the environmental conditions associated with each type of boundary layer circulation would clarify the environmental influences on circulation type in addition to helping modelers and forecasters better predict boundary layer organization. Thus, the dataset created by Banghoff et al. (2020) is used to identify cases representing the three circulation types. The environmental conditions for these cases are determined from routinely available observations and differences between the environments of HCRs, cells, and nulls explored. Only cases that display a single circulation type are selected for study, with the resulting dataset consisting of 50 cases per circulation type: HCR, cell, and null. The size of the dataset should yield enough variability to examine which environmental parameters are associated with the three circulation types. The potential for an operational method to determine whether HCRs, cells, or null cases are more likely in a given environment also is investigated.

Section 2 describes the observational datasets and analysis methods used. This discussion is followed by analysis results in section 3, which includes both a comparison of the mean environmental conditions for the three circulation types as well as results from a multiclass linear discriminant analysis. A summary is found in section 4.

\section{Data and methods}

Warm-season Doppler radar and Oklahoma Mesonet observations from central Oklahoma from 2013 to 2017 are used to create a dataset of 50 cases each of HCRs, cells, and null 


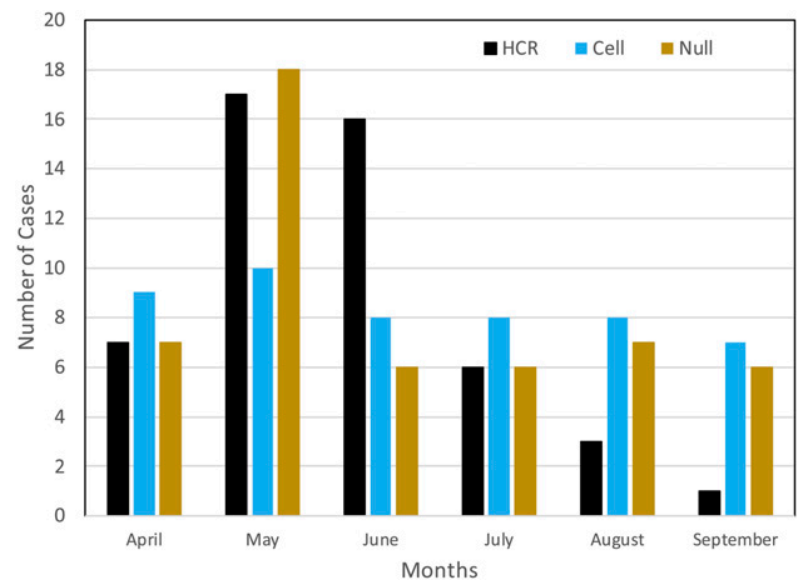

FIG. 1. Number of cases plotted as a function of month during the warm season from April to September of HCRs (black), cells (blue), and null events (brown). Cases were selected from the years 2013-17 using the database from Banghoff et al. (2020).

cases from the dataset of Banghoff et al. (2020). The cases selected for subsequent analysis display only a single circulation type (HCR, cell, or null), even though HCRs transition to or from cellular convection on roughly one-third of the cases (Banghoff et al. 2020) and hybrid HCR and cell events have been observed in other studies (Grossman 1982; LeMone et al. 2010). Only data from 2013 and later are used owing to the need for dual-polarization WSR-88D observations at the Twin Lakes (KTLX) radar to estimate $Z_{i}$. The cases span all 6 months, although HCR cases are more common in May and June and there is only one HCR case in September (Fig. 1). Cell and null cases are spread fairly evenly throughout the warm-season months, although there are more null cases in May than the other months.

\section{a. Oklahoma Mesonet observations}

Oklahoma Mesonet stations consist of $10-\mathrm{m}$ towers that collect wind observations at 2 and $10 \mathrm{~m}$ above ground level (AGL), temperature and relative humidity at 1.5 and $9 \mathrm{~m}$ AGL, and atmospheric pressure, rainfall, solar radiation, and soil temperature and soil moisture at three depths (McPherson et al. 2007). The Mesonet has been in operation since 1994, and it has grown over time to 120 stations, with at least one Mesonet station in each of the 77 counties in Oklahoma. Observations from the Mesonet are collected every minute, and 5-min-average values are reported for most variables (Brock et al. 1995; McPherson et al. 2007). The instrumentation used by the Oklahoma Mesonet is reported in McPherson et al. (2007).

Oklahoma Mesonet stations underneath the cone of the KTLX WSR-88D surveillance scans are used to determine surface conditions and to estimate surface SHF and $u_{*}$. These stations are the Norman, Shawnee and Spencer, Oklahoma, sites (Fig. 2), and all three sites are grass covered as is typical for central Oklahoma. It is assumed that the near-surface environment is horizontally homogeneous under the radar cone to a distance of $40 \mathrm{~km}$ from KTLX such that the Mesonet

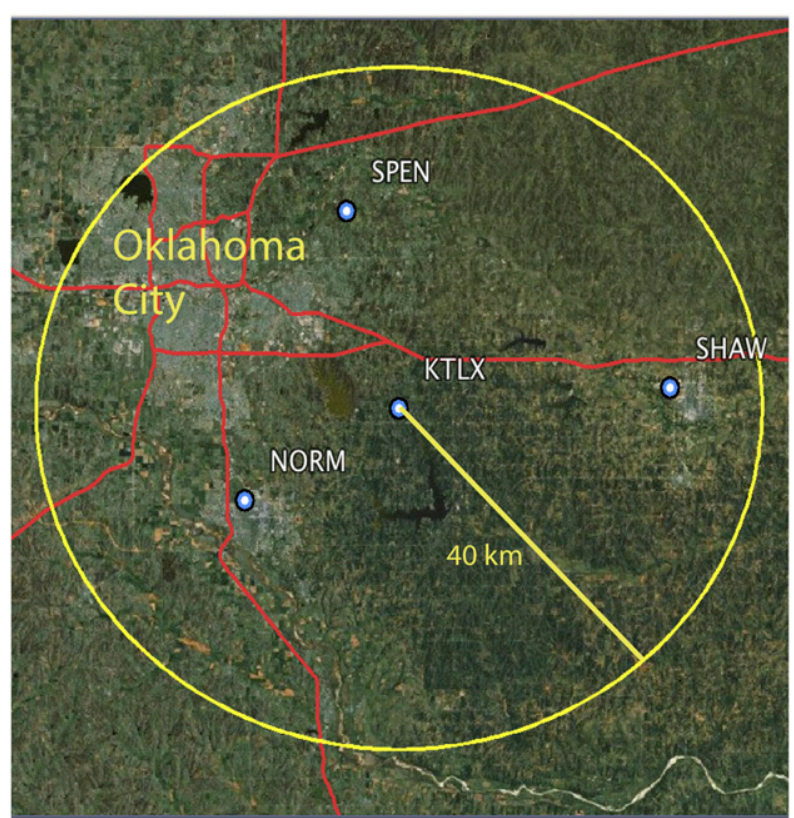

FIG. 2. Region around the KTLX WSR-88D in central Oklahoma, including the Norman (NORM), Spencer (SPEN), and Shawnee (SHAW) Oklahoma Mesonet sites and the 40-km radar range ring. The locations of Oklahoma City and major roadways are indicated.

station density is sufficient to provide reasonable estimates of the surface variables calculated.

The profile gradient method as outlined in Brotzge and Crawford (2000) is used to estimate SHF. While surface buoyancy flux is most relevant to boundary layer structure, it is very hard to measure and so SHF commonly is used instead. The estimation method is based on dynamical theory discussed by Panofsky (1963) and Paulson (1970) and requires wind speed and temperature observations at two heights. The SHF is estimated every $5 \mathrm{~min}$ using the Mesonet observations at the three sites. Results show that the value of SHF on subhourly time scales can be particularly noisy owing to the influence of low-level clouds, yet it is the hourly trends in SHF that tend to impact the boundary layer circulation (Weckwerth et al. 1996). To reduce the noise in the SHF estimates, a five-point median filter is applied to the SHF time series from 0000 to 2355 UTC on each day for each of the three Mesonet stations. The filtered values of SHF at each of the three stations are then averaged to provide a mean value of SHF every $5 \mathrm{~min}$, which is used in our subsequent calculations and the analyses.

Oklahoma Mesonet observations also are used to calculate $\theta_{v}$, the friction velocity $u_{*}$, and the Obukhov length $L$ every 5 min at each station; $\theta_{v}$ is calculated from Mesonet observations of temperature, pressure and relative humidity at $2 \mathrm{~m}$, and $u_{*}$ is a function of the Reynolds stress at the surface and is calculated directly from Mesonet data using wind observations and adjustments due to stability, as in Brotzge and Crawford (2000). The 5-min values of $\theta_{v}$ and $u_{*}$ are averaged over the three Mesonet stations. The Obukhov length is the height AGL when buoyant forces start to dominate over wind shear in 
the generation of turbulence, and it is negative in convective environments. The Obukhov length is calculated from

$$
L \approx \frac{-\rho c_{p} \theta_{v} u_{*}^{3}}{k g \times \mathrm{SHF}},
$$

where $k=0.4$ is the von Kármán constant, $g=9.81 \mathrm{~m} \mathrm{~s}^{-2}$ is the gravitational acceleration, $c_{p}=1004 \mathrm{~J} \mathrm{~kg}^{-1} \mathrm{~K}^{-1}$ is the specific heat at constant pressure, and $\rho$ is the air density, which is the average calculated from the three Mesonet stations every $5 \mathrm{~min}$. As mentioned above, it also is assumed that SHF is a reasonable estimate for the surface buoyancy flux. Last, the free convective scaling velocity $w_{*}$ can be thought of as a typical updraft speed for convective thermals in the CBL (Stull 1988) and is calculated from

$$
w_{*}=\left(\frac{g Z_{i}}{\rho c_{p} \theta_{v}} \times \mathrm{SHF}\right)^{1 / 3},
$$

where SHF is again used instead of buoyancy flux and SHF, $\theta_{v}$, and $\rho$ are 5-min average values calculated as previously described, and $Z_{i}$ is determined from the $Z_{\mathrm{DR}}$ observations following Banghoff et al. (2018), which is explained below. Both $L$ and $w_{*}$ are calculated every $5 \mathrm{~min}$.

\section{b. KTLX WSR-88D observations}

The KTLX WSR-88D is located to the southeast of the Oklahoma City metropolitan area (Fig. 2) at an altitude of $338 \mathrm{~m}$ MSL. This radar was upgraded to have dual-polarization (hereinafter dual-pol) capabilities in 2012. The WSR-88D observations typically are available every $10 \mathrm{~min}$ when the radar is in clear-air mode and every $4 \mathrm{~min}$ when in precipitation mode. For majority of the cases selected, KTLX observations are every $10 \mathrm{~min}$. Radar observations are used to estimate the mean CBL winds $U_{\mathrm{CBL}}$, the mean CBL wind shear $d U / d z$, and $Z_{i}$ and to identify the circulation type. As discussed in Banghoff et al. (2018), Bragg scattering is often found near the top of the CBL and is characterized by $Z_{\mathrm{DR}}$ values close to $0 \mathrm{~dB}$ (see also Melnikov et al. 2011, 2013; Davison et al. 2013; Richardson et al. 2017a,b). Thus, the value of $Z_{\mathrm{DR}}$ can be used to distinguish between biological scatterers, which have much larger values of $Z_{\mathrm{DR}}$, and the turbulent features that cause the Bragg scatter zone, which has much lower $Z_{\mathrm{DR}}$, and hence can be used to diagnose $Z_{i}$ (Banghoff et al. 2018).

The value of $Z_{i}$ is calculated over the radar sampling volume using the QVP technique described by Kumjian et al. (2013) and Ryzhkov et al. (2016). A time series of QVPs of $Z_{\mathrm{DR}}$ is created from 1200 to 0000 UTC (subtract $6 \mathrm{~h}$ to obtain local time) to encompass the daytime development of the CBL. From this QVP time series, the vertical minimum of $Z_{\mathrm{DR}}$ is determined for each observation time throughout the daytime hours by visual inspection and defines the value of $Z_{i}$. In the cases of multiple minimum zones, the center of the bottom minimum zone is taken to be the value of $Z_{i}$. In case of a large minimum zone $(\sim 200 \mathrm{~m}$ thickness $)$, the bottom of the zone is taken to be the value of $Z_{i}$. The values of $Z_{i}$ vary smoothly over the daytime hours and are interpolated to 5-min intervals.
The VAD method is used to calculate the environmental winds as a function of height AGL within the radar sampling volume (Browning and Wexler 1968). The VAD method is applied to each range gate for radar elevations of $0.5^{\circ}$ and $1.5^{\circ}$ and then binned in 50-m vertical intervals from $220 \mathrm{~m}$ AGL (lowest altitude of the first radar measurement used) to the top of the CBL at $Z_{i}$. The VAD winds represent an average wind speed within the radar volume. Knowledge of the mean CBL winds at 50-m vertical intervals allows for easy calculation of $U_{\mathrm{CBL}}$ over any averaging period. Wind shear $d U / d z$ is calculated by taking the difference between the wind velocity at the top of the CBL $\left(U_{Z_{i}}\right)$ and wind velocity at $10 \mathrm{~m}$ from the Oklahoma Mesonet and dividing by $\left(Z_{i}-10 \mathrm{~m}\right)$ following Weckwerth et al. (1997).

To classify boundary layer circulations into HCR, cell, or null cases, Banghoff et al. (2020) use a plan position indicator (PPI) plot of radar reflectivity factor at horizontal polarization, $Z_{H}$, to manually investigate the PPI plots looped over the daytime hours. Since $Z_{H}$ values for atmospheric biota are typically $<20 \mathrm{~dB} Z, Z_{H}$ is displayed in the range from -10 to $25 \mathrm{~dB} Z$. This range makes it much easier to observe biota and also aids in identifying precipitation and deep convection that may impact the circulations. Loops of $Z_{H}$ at an elevation angle of $1.5^{\circ}$ are used to identify start times and end times for boundary layer circulations, with the $1.5^{\circ}$ angle being used to reduce ground clutter contamination present at the lowest elevation. The classification of boundary layer circulations for each case is revisited here by visual inspection and the classifications confirmed (Fig. 3). HCRs are identified by their long $Z_{H}$ bands, with their orientation being about parallel to the mean wind in the CBL (Fig. 3a). Cells are identified by their polygonal or circular shapes on the $Z_{H}$ returns (Fig. 3b). Null cases are identified by their lack of organizational structure (Fig. 3c), which could happen primarily for two reasons: the environment is not conducive for boundary layer circulation organization or there is insufficient biota to cause $Z_{H}$ returns. To avoid the latter situation, null cases in this study are required to have sufficient $Z_{H}$ returns above $20 \mathrm{~dB} Z$ in this study. The classification necessarily is subjective and focused upon the entire reflectivity field surrounding the radar and not just one region of this field. It is possible that HCRs and cells could be active simultaneously, as seen in Grossman (1982) and LeMone et al. (2010), and underlying terrain features also may play a role in local deviations from the classical linear and polygonal patterns. Animation of the PPIs on the days selected suggests that the HCR cases selected here represent only a single circulation type and are not a hybrid of the two circulation types, although the cell cases are more complex and may at times be a hybrid of the two circulation types.

\section{c. Linear discriminant analysis}

Fisher (1936) outlines a process by which one can discriminate group membership on the basis of observed attributes, which for this study translates into determining CBL circulation type (HCR, cell, or null) using environmental observations. Given a set of training data from each of two known groups, linear discriminant analysis (LDA) creates a linear 

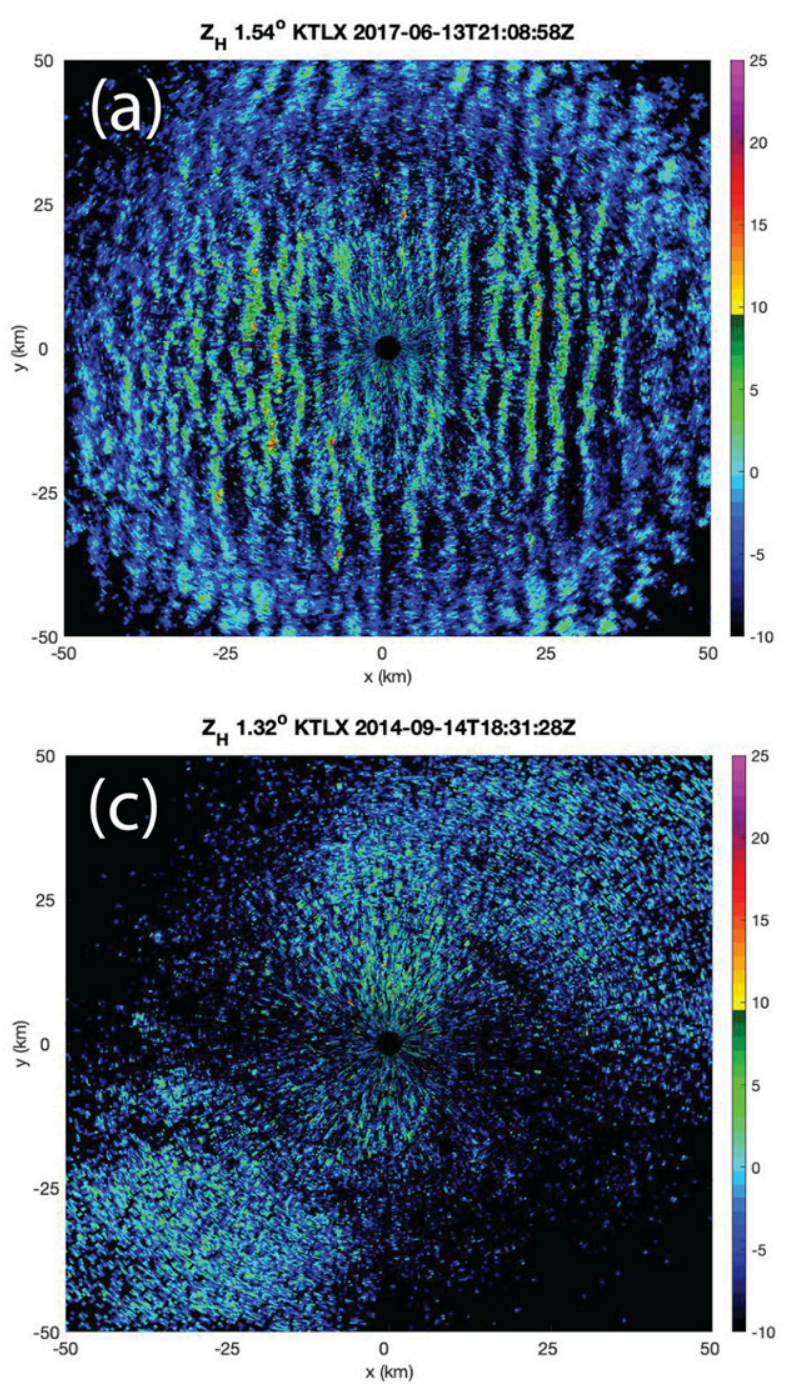

function $D$ for each group that combines the observed attributes $X$, with

$$
D_{g}=a_{1} X_{g, 1}+a_{2} X_{g, 2}+\cdots+a_{p} X_{g, p}
$$

where $a_{i}$ are the weights calculated by the technique and $X_{g, i}$ are the $i=1,2, \ldots, p$ observed attributes from the $g=1,2$ groups. Details on how the weights are calculated can be found in Wilks (2006). The only assumption is that the underlying covariance matrices are equal for the two groups; if the covariance matrices are unequal then the discrimination will be less accurate but still may be very useful. Either dimensional or dimensionless data can be used as attributes, providing great flexibility when exploring datasets. One can view LDA as a way to calculate a function that maximizes the separation of the group means. Once the weights are determined from the training data, $D$ can be calculated for any $X$ and group membership determined by whether the value of $D$ is closer to the mean value of $\overline{D_{1}}$ or $\overline{D_{2}}$ calculated from the training data (see Wilks 2006). This same approach is called multiclass discriminant

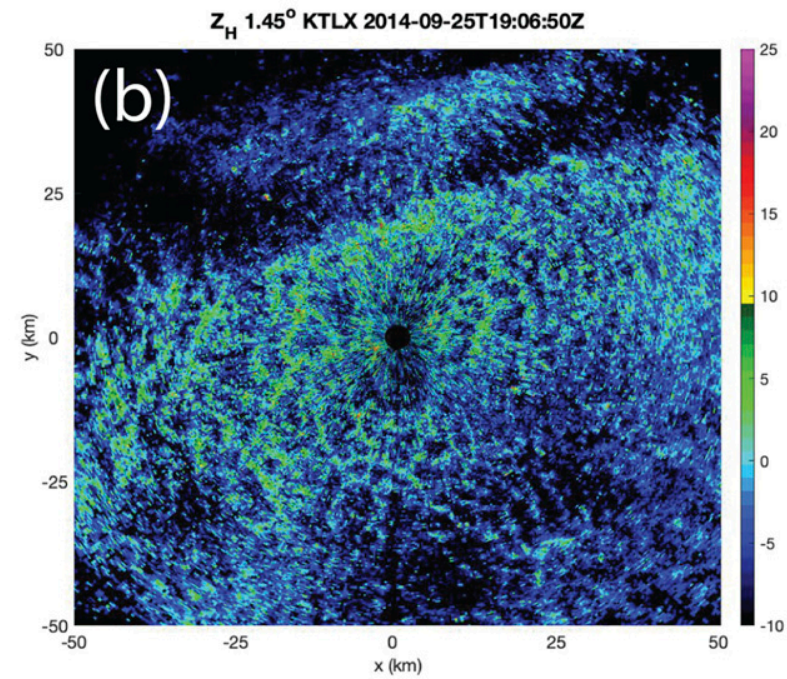

FIG. 3. Equivalent radar reflectivity factor $Z_{H}$ at $1.4^{\circ}$ for (a) HCR, (b) cell, and (c) null events as sampled from the Twin Lakes (KTLX) WSR-88D. The HCR signature has a distinct linear structure in the reflectivity field, whereas the cell signature has circular to hexagonal features in a honeycomb-like collection. The null signature has a much more random reflectivity field. These signatures are typical of the patterns seen for the three circulation types.

analysis (MDA) when extended to three or more groups (Rao 1948).

For the present study the groups are HCR, cell and null events, and the attributes are $\mathrm{SHF}, L, u_{*}, w_{*}, Z_{i}, U_{\mathrm{CBL}}$, and $d U / d z$. General guidance is that at least 5 cases are needed for each attribute (Viana and Sansigolo 2016) and since this study uses seven variables as attributes, the observational dataset should have at least 35 cases for each group; thus, 50 cases are used for each group in this study. Because there are three classification groups, three pairwise combinations of classes are used with LDA to discriminate between (i) HCRs and cells, (ii) HCRs and nulls, and (iii) cells and nulls. Information on the observed frequency of HCRs, cells, and nulls is not used in MDA; it is assumed that the groups are equally likely and so for a three-group classification a $33.3 \%$ correct rate is the expected correct percent value for a random selection. A probabilistic classification approach is applied to the results of the three LDAs to determine into which group the observations on a given day belong (Wilks 2006). The group associated with the highest 
probability is selected for each day. See Wilks (2006) for further details.

With data that vary greatly in magnitude and variance, such as seen in $u_{*}$ and $Z_{i}$ for instance, the equal covariance matrices assumption is likely invalid. Thus, a rescaling is applied wherein the natural logarithm of the data values is used. This rescaling is important because small variations in the data become larger and large variations in the data become smaller, thereby helping to make the variances and covariances more equal among the different variables and approaching the assumptions for MDA. The matrix-to-matrix correlations vary from 0.80 to 0.96 for the three covariance matrices, suggesting that the covariance matrices are similar. Testing confirms that MDA results are improved when the natural logarithm rescaling is applied to the variables.

To explore which observed variables are most important to discriminating between HCRs, cells, and nulls, the MDA is provided with all possible 120 variable combinations from two variables to seven variables. As discussed in the next section, some of these variables are highly correlated, such as SHF and $w_{*}$ (correlation of 0.86 in the training data) and $U_{\mathrm{CBL}}$ and $d U / d z$ (correlation of 0.83 in the training data), and therefore contain redundant information. Yet correlated variables are still provided to MDA since at worst this situation will simply result in little improvement in discrimination and at best it may be that even limited amounts of independent information will improve the discrimination. The variables that result in the best discrimination between the groups are the observations most important to correctly predicting circulation type and thus may be keys to understanding the physical processes that underlie the differences in circulation type.

Once the observations and parameters from the Oklahoma Mesonet stations (SHF, $L$, and $u_{*}$ ), the KTLX WSR-88D $\left(U_{\mathrm{CBL}}\right.$ and $\left.Z_{i}\right)$, and the convective scaling velocity $w_{*}$ and wind shear $d U / d z$ that require observations from both Mesonet and radar, are calculated at the available observation times (Mesonet data every $5 \mathrm{~min}$, KTLX data and parameters that use KTLX data every 5-10 min depending upon volume scan in use), the observations and parameters are averaged in time for each case. The averaging is applied over the lifetime of the circulation, that is, from the start of the circulation to its demise, and thus the averaging time length varies for each HCR and cell case. This choice results in averaging times between 1.5 and $8 \mathrm{~h}$. For null events, the time averaging is applied uniformly from 1800 to 2200 UTC, or over $4 \mathrm{~h}$ so that the mean averaging time period is similar for all cases in the training data. The time mean values for each case are used in the subsequent analyses because they are more representative of the environmental conditions for HCRs, cells, and nulls than values averaged over 5 or $10 \mathrm{~min}$ and should help to discriminate between the environments of the three groups.

The potential for an operational method to determine whether HCRs, cells, or null cases are more likely to occur on a given day is explored with a smaller independent dataset. Instead of averaging observations over the time period of the circulations, a shorter averaging time is used and chosen to be the 30-min period prior to the start time of HCRs or cells. For null events with no defined start time, the averaging period is
TABLE 1 . Time-averaged values of SHF, $L, u_{*}, U_{\mathrm{CBL}}, d U / d z, Z_{i}$, and $w_{*}$ calculated using the 50 cases each for HCRs, cells, and nulls. The largest values from the three circulation types are shown in boldface type, and smallest values are shown in italics.

\begin{tabular}{lccc}
\hline \hline \multicolumn{1}{c}{ Variable } & HCRs & Cells & Nulls \\
\hline SHF $\left(\mathrm{W} \mathrm{m}^{-2}\right)$ & 122 & $\mathbf{1 3 4}$ & 114 \\
$L(\mathrm{~m})$ & -86 & $\mathbf{- 2 1}$ & -53 \\
$u_{*}\left(\mathrm{~m} \mathrm{~s}^{-1}\right)$ & $\mathbf{0 . 3 7}$ & 0.23 & 0.28 \\
$U_{\mathrm{CBL}}\left(\mathrm{m} \mathrm{s}^{-1}\right)$ & $\mathbf{9 . 1}$ & 3.5 & 5.9 \\
$d U / d z\left(\mathrm{~s}^{-1}\right)$ & $\mathbf{4 . 2} \times \mathbf{1 0}^{-\mathbf{3}}$ & $1.2 \times 10^{-3}$ & $3.0 \times 10^{-3}$ \\
$Z_{i}\left(\mathrm{~m}^{-1}\right.$ & $\mathbf{1 2 8 2}$ & 1271 & 1043 \\
$w_{*}\left(\mathrm{~m} \mathrm{~s}^{-1}\right)$ & 1.48 & $\mathbf{1 . 5 1}$ & 1.33 \\
\hline
\end{tabular}

from 1800 to 1830 UTC. A total of 50 additional cases (17 HCR, 17 cells, and 16 null) are used to test the usefulness of the MDA approach as a predictive tool. Observations from both the KTLX WSR-88D and the three Oklahoma Mesonet stations are used, with cases again taken from the dataset of Banghoff et al. (2020) except that different case days are chosen.

The ability of various methods to predict whether HCRs, cells, or null cases occur based upon environmental conditions is evaluated in several related ways. Percent correct is simply the percentage of case days correctly identified for a particular circulation type. Mean percent correct is the average percent correct for all three circulation types. Weighted mean percent correct is the percent correct weighted by the observed frequencies of the three circulation types found by Banghoff et al. (2020), or $71 \%$ HCRs, $21 \%$ cells, and $7 \%$ null cases. Here the percent correct for HCRs is weighted 3.4 times more than the percent correct for cells and 10.1 times more than the percent correct for null cases.

\section{Results}

\section{a. Mean environmental conditions and correlations}

The mean values of the seven environmental variables calculated from the $50 \mathrm{HCR}$, cell, and null cases are summarized in Table 1, although there is considerable spread around the means. Mean values of SHF are positive for the three circulation types, as expected for a daytime CBL, with cells having slightly larger mean SHF and $w_{*}$ than either HCRs or nulls. $L$ varies from -2 to $-343 \mathrm{~m}$ across all cases, with cells having the least negative mean value of $L$. Slightly larger SHF and $w_{*}$, along with a less negative value of $L$, suggest a more convectively forced $\mathrm{CBL}$ on days with cells.

Correlations between the seven environmental variables are calculated using data from all 150 cases and reported in Table 2. Results show that $U_{\mathrm{CBL}}$ is positively correlated with $d U / d z$ and $u_{*}$, and negatively correlated with $L$, at values above 0.66 , suggesting that much of their variations are dominated by the variation in low-level wind shear magnitude. However, these observations also contain independent information as their intercorrelations explain less than $70 \%$ of their variations. SHF and $w_{*}$ is the most highly correlated variable pair in the dataset and both have moderate correlations with $L$ and negligible correlations with $U_{\mathrm{CBL}}, d U / d z$, and $u_{*}$. 
TABLE 2. Correlations between the seven environmental variables calculated using observations from all 150 cases in the training dataset.

\begin{tabular}{lccccccr}
\hline & $U_{\mathrm{CBL}}$ & $d U / d z$ & $L$ & $u_{*}$ & $w_{*}$ & $\mathrm{SHF}$ & \multicolumn{1}{c}{$Z_{i}$} \\
\hline$U_{\mathrm{CBL}}$ & 1 & 0.83 & -0.73 & 0.66 & -0.15 & -0.14 & 0.12 \\
$d U / d z$ & & 1 & -0.64 & 0.42 & -0.34 & -0.22 & -0.15 \\
$L$ & & & 1 & -0.37 & 0.44 & 0.41 & -0.12 \\
$u_{*}$ & & & & 1 & 0.34 & 0.28 & -0.04 \\
$w_{*}$ & & & & & 1 & 0.86 & 0.18 \\
$\mathrm{SHF}$ & & & & & & 1 & -0.16 \\
$Z_{i}$ & & & & & & & 1 \\
\hline
\end{tabular}

These relationships also are consistent with the expectation that variations in $w_{*}$ are dominated by variations in buoyancy (characterized by SHF), which is independent of wind shear. In contrast, $L$ is negatively correlated with $U_{\mathrm{CBL}}, d U / d z$, and $u_{*}$ supporting the idea that the height at which buoyant forces dominate over shear is higher as the wind shear increases. Last, $Z_{i}$ has negligible correlations with all other variables, consistent with the expectation that the depth of the circulations is independent of wind shear magnitude and buoyancy.

A threshold value of $U_{\mathrm{CBL}} \sim 6 \mathrm{~m} \mathrm{~s}^{-1}$ for HCRs has been suggested in other studies (Woodcock 1940; Deardorff 1976; Weckwerth et al. 1997) to discriminate between HCRs and cells. In the $50 \mathrm{HCR}$ cases explored here, there are only 5 cases with $U_{\mathrm{CBL}}$ less than $6 \mathrm{~m} \mathrm{~s}^{-1}$ and the smallest case value of $U_{\mathrm{CBL}}$ for HCRs is $4.6 \mathrm{~m} \mathrm{~s}^{-1}$. In contrast, the cell mean value of $U_{\mathrm{CBL}}$ is $3.5 \mathrm{~m} \mathrm{~s}^{-1}$ and only 5 cell cases have $U_{\mathrm{CBL}}>6 \mathrm{~m} \mathrm{~s}^{-1}$. This suggests that a $U_{\mathrm{CBL}}$ of $6 \mathrm{~m} \mathrm{~s}^{-1}$ is indeed a reasonable threshold value for discriminating between HCRs and cells, yielding a correct discrimination $90 \%$ of the time in the training data. Unfortunately, a scatterplot of $U_{\mathrm{CBL}}$ and $w_{*}$ from all cases shows that a $6 \mathrm{~m} \mathrm{~s}^{-1}$ threshold for $U_{\mathrm{CBL}}$ has little ability to separate out null events from the other two circulation types, as 32 null cases have $U_{\mathrm{CBL}}<6 \mathrm{~m} \mathrm{~s}^{-1}$ and 18 null cases have $U_{\mathrm{CBL}}>6 \mathrm{~m} \mathrm{~s}^{-1}$ (Fig. 4). This scatterplot also shows that HCRs, cells, and nulls share similar ranges of $w_{*}$, suggesting that larger values of $w_{*}$ and SHF, indicative of a more convectively forced CBL, do not lead to cells becoming more common as might be expected. In addition, $w_{*}$ by itself is unable to distinguish between any of the circulation types.

Weckwerth et al. (1997) found that HCRs are present for $d U / d z>2 \times 10^{-3} \mathrm{~s}^{-1}$, cells are present for $d U / d z$ roughly below this value, and null and unorganized convection is associated with $d U / d z$ values shared by both HCRs and cells. Applying a $2 \times 10^{-3} \mathrm{~s}^{-1} d U / d z$ threshold to the current dataset yields an $87 \%$ correct discrimination between HCRs and cells in the training data (Fig. 5), slightly less than found using $U_{\mathrm{CBL}}$, while $d U / d z$ does not help to separate out null events (27 of 50 null events have $d U / d z$ in excess of this threshold). This result agrees well with the analysis of Weckwerth et al. (1997). The mean $d U / d z$ from the $50 \mathrm{HCR}$ cases is $4.2 \times 10^{-3} \mathrm{~s}^{-1}$, with a range of CBL wind shear from $9 \times 10^{-4}$ to $1.3 \times 10^{-2} \mathrm{~s}^{-1}$; this range of $d U / d z$ values exceeds those reported by Weckwerth et al. (1997) and the minimum value of $d U / d z$ suggests that the $d U / d z$ needed to support HCRs is very small. The $d U / d z$ range

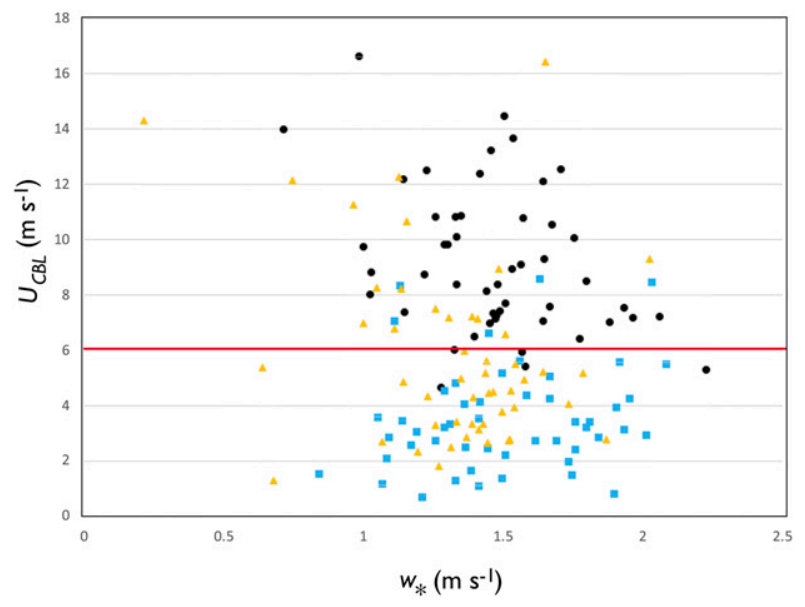

FIG. 4. Scatterplot of $w *\left(\mathrm{~m} \mathrm{~s}^{-1}\right)$ vs $U_{\mathrm{CBL}}\left(\mathrm{m} \mathrm{s}^{-1}\right)$ for the 50 cases each of HCR (black circles), cell (blue squares), and null (brown triangles) in the dataset. The horizontal red line indicates the $6 \mathrm{~m} \mathrm{~s}^{-1}$ value of $U_{\mathrm{CBL}}$ that provides a reasonable threshold value to separate HCR and cell cases.

for cells is from $8.6 \times 10^{-5}$ to $5.4 \times 10^{-3} \mathrm{~s}^{-1}$, overlapping with the lower range of wind shear values for HCRs, while nulls have the largest $d U / d z$ range of $1.7 \times 10^{-5}$ to $1.0 \times 10^{-2} \mathrm{~s}^{-1}$. A closer look at the values of $Z_{i}$ in Table 1 and Fig. 5 show that this variable may provide some useful discrimination between nulls and HCRs or cells, as the mean value of $Z_{i}$ is nearly $200 \mathrm{~m}$ less for nulls. Using a threshold value of $1100 \mathrm{~m}$ for $Z_{i}$, with values larger indicating HCRs or cells and values smaller indicating nulls, yields a $68 \%$ correct discrimination (Fig. 5). The large spread in values around the means continues to make discrimination of nulls challenging.

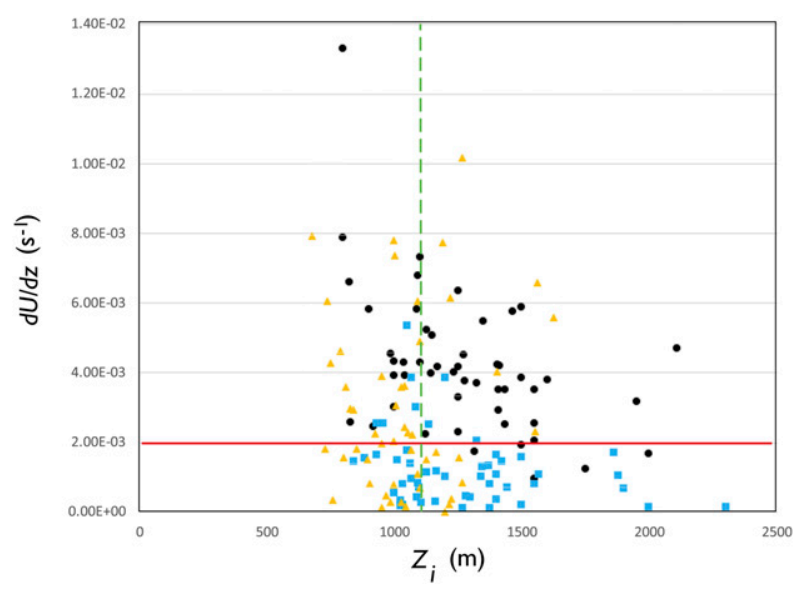

FIG. 5. Scatterplot of $Z_{i}(\mathrm{~m})$ vs $d U / d z\left(\times 10^{-3} \mathrm{~s}^{-1}\right)$ for the 50 cases each of HCR (black circles), cell (blue squares), and null (brown triangles) in the dataset. The horizontal red line indicates the $2 \times 10^{-3} \mathrm{~s}^{-1}$ value of $d U / d z$ that provides a reasonable threshold value to separate HCR and cell cases, and the vertical green dashed line indicates the $1100-\mathrm{m}$ value of $Z_{i}$ that helps to separate null events from the other circulation types. 
A similar general outcome occurs when $u_{*}$ and SHF values are evaluated. The mean value of $u_{*}$ in the dataset is largest for HCRs and smallest for cells, as expected as the correlation between $u_{*}$ and $U_{\mathrm{CBL}}$ is 0.66 , with a similar value ranges among all three circulation types (not shown). Using a threshold $u_{*}$ value of $0.30 \mathrm{~m} \mathrm{~s}^{-1}$ to discriminate between HCRs and cells, the dataset yields an $87 \%$ correct discrimination between the two in the training data (Fig. 6). Yet again there is little ability to further discriminate null cases. The largest values of SHF are associated with cells, although cells also have the greatest spread of SHF, and with HCRs having the narrowest distribution of SHF. However, there is no obvious threshold value for SHF that would distinguish between the circulation types.

As these analyses suggest, the differences in mean environmental conditions between null, cell and HCR cases are not large, with the mean environmental properties of nulls in between the mean values for HCRs and cells. Based upon these comparisons, it appears that a threshold value of $U_{\mathrm{CBL}}=$ $6 \mathrm{~m} \mathrm{~s}^{-1}$ is slightly more helpful than the other environmental variables in discriminating between HCRs and cells, although none of the observations is particularly helpful at identifying null cases.

The selected threshold value for $U_{\mathrm{CBL}}$ is further evaluated using the smaller 50 case independent dataset of environmental conditions. The ranges of observational values in the independent dataset are very similar to those in the training dataset, with many of the relative orderings of the mean values from the three groups identical (e.g., mean $U_{\mathrm{CBL}}$ largest for HCRs and smallest for cells, $w_{*}$ largest for cells and smallest for nulls). When this mean wind speed threshold is applied to the independent dataset, $76 \%$ of the HCR cases and $71 \%$ of the cell cases are identified correctly. If we take into account the observed frequencies of the three groups from Banghoff et al. (2020) and acknowledge the lack of any ability to predict nulls, then the weighted mean percent correct discrimination is $69 \%$. Yet there are hints in the scatterplots that other variables provide some information on circulation type, suggesting that a more quantitative approach is needed to maximize the value of the larger dataset to determine the environmental conditions associated with the three CBL circulation types.

\section{b. Discriminant analysis}

MDA is applied to the data for HCRs, cells and nulls given various variable combinations to determine: 1 ) the observation(s) most important to correctly predicting circulation type; 2 ) whether the resulting discriminant functions provide insight into the physical processes governing circulation type; and 3) whether environmental conditions can be used to predict circulation type. Because some of the scatterplots show ability to distinguish between HCRs and cells with only two variables, the MDA is first applied using only two variables from the training data. All the possible two-variable combinations are used in the MDA, yielding a total of 21 combinations. A probabilistic classification rule is applied to the resulting LDA output and the predicted group is compared to the observed group (HCR, cell, null). The correct assignment of groups is then calculated as a percent correct for HCR, cell, and null groups, and a mean percent correct for all three groups. It is assumed that the three

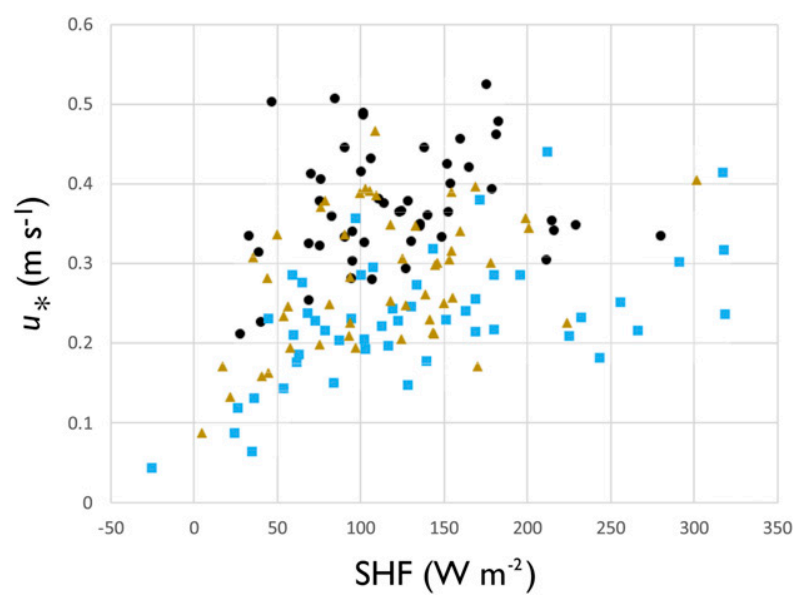

FIG. 6. Scatterplot of SHF $\left(\mathrm{W} \mathrm{m}^{-2}\right)$ vs $u_{*}\left(\mathrm{~m} \mathrm{~s}^{-1}\right)$ for the 50 cases each of HCR (black circles), cell (blue squares), and null (brown triangles) in the dataset.

groups are equally likely, such that a percent correct greater than $33.3 \%$ shows skill above a random guess. We first explore the results from the training data and then apply the resulting MDA to the test dataset.

Results from the training data indicate that correctly predicting null events is the most difficult, with many of the twovariable combinations yielding $<50 \%$ correct and a mean of $45 \%$ correct for null cases for all 21 variable combinations (Table 3). The variable that is most useful in predicting null events is $Z_{i}$. As discussed earlier, the mean $Z_{i}$ value is $\sim 200 \mathrm{~m}$ smaller for null events than for either HCRs or cells. This result may be attributed to case selection, or it may be that the presence of vertical circulations within the boundary layer leads to deeper CBLs than would otherwise occur. Though null cases occur on only $7 \%$ of the days without precipitation (Banghoff et al. 2020), little else is known about why coherent circulations do not occur on these days with favorable environmental conditions.

The HCR group is the easiest to predict correctly, with $\geq 80 \%$ correct when $U_{\mathrm{CBL}}$ is one of the two-variable subsets in Table 3 . For cells, $\geq 70 \%$ correct occurs for over one-half of the subsets, although the mean from all subsets for cells is only $4 \%$ less than the mean for HCRs (i.e., 69\% correct for HCRs, $65 \%$ correct for cells). Replacing $U_{\mathrm{CBL}}$ with $d U / d z$ in the twovariable MDA yields an $21 \%$ decrease in percent correct for HCRs, yet yields a similar percent correct for cells and nulls, further suggesting that CBL wind shear by itself is not a useful discriminator of circulation type.

The largest mean percent correct using a two-variable combination MDA applied to the training data includes $U_{\mathrm{CBL}}$ and $Z_{i}$ and yields a $69 \%$ mean percent correct, yet even for this subset null cases are only $56 \%$ correct (Table 3 ). One can increase the percent correct to $76 \%$ for nulls using the subset $w_{*}$ and $Z_{i}$, but at the cost of decreasing the correct prediction for HCRs to $30 \%$. Even with smaller SHF and $w_{*}$, the median value of $Z_{i} / w_{*}$ is smaller for nulls compared to HCRs and cells, suggesting that thermals reach the top of the CBL more rapidly for null cases. 
TABLE 3. Percent correct and mean percent correct for identifying the CBL circulation type (HCR, cell, or null) of various combinations of environmental observations when used in MDA. The 21 combinations of two variables are shown first, followed by the best-performing 3-, 4-, 5-, 6-, and 7-variable combination results, listing the variables used in the MDA. Results are compared with the training data. Weighted mean percent correct is calculated from the independent test dataset.

\begin{tabular}{|c|c|c|c|c|c|c|}
\hline Variable 1 & Variable 2 & HCR & Cell & Null & Mean percent correct & Weighted mean percent correct \\
\hline$U_{\mathrm{CBL}}$ & SHF & 88 & 70 & 36 & 65 & 58 \\
\hline$U_{\mathrm{CBL}}$ & $u_{*}$ & 86 & 68 & 44 & 66 & 55 \\
\hline$U_{\mathrm{CBL}}$ & $w_{*}$ & 86 & 76 & 36 & 66 & 57 \\
\hline$U_{\mathrm{CBL}}$ & $-L$ & 84 & 72 & 34 & 63 & 57 \\
\hline$U_{\mathrm{CBL}}$ & $d U / d z$ & 84 & 74 & 44 & 67 & 46 \\
\hline$u_{*}$ & $d U / d z$ & 78 & 76 & 44 & 66 & 65 \\
\hline$-L$ & $w_{*}$ & 82 & 70 & 24 & 59 & 53 \\
\hline$d U / d z$ & SHF & 58 & 70 & 30 & 53 & 69 \\
\hline$U_{\mathrm{CBL}}$ & $Z_{i}$ & 80 & 72 & 56 & 69 & 35 \\
\hline$d U / d z$ & $w *$ & 56 & 70 & 28 & 51 & 70 \\
\hline$u_{*}$ & $w *$ & 78 & 64 & 42 & 61 & 66 \\
\hline$u_{*}$ & $-L$ & 76 & 74 & 34 & 61 & 68 \\
\hline$d U / d z$ & $Z_{i}$ & 62 & 60 & 52 & 58 & 28 \\
\hline$u_{*}$ & $Z_{i}$ & 72 & 52 & 64 & 63 & 31 \\
\hline$d U / d z$ & $-L$ & 64 & 80 & 38 & 61 & 33 \\
\hline$u_{*}$ & SHF & 72 & 72 & 32 & 59 & 72 \\
\hline$-L$ & SHF & 68 & 72 & 32 & 57 & $\overline{48}$ \\
\hline$-L$ & $Z_{i}$ & 64 & 70 & 60 & 65 & 24 \\
\hline SHF & $Z_{i}$ & 50 & 20 & 74 & 48 & 22 \\
\hline$w_{*}$ & $Z_{i}$ & 30 & 36 & 76 & 47 & 19 \\
\hline$w *$ & SHF & 26 & 40 & 56 & 41 & 40 \\
\hline & Variables in best $M D A$ & & & & & \\
\hline MDA3 & $U_{\mathrm{CBL}}, u_{*}$, and $Z_{i}$ & 82 & 72 & 66 & 73 & 31 \\
\hline MDA4 & $U_{\mathrm{CBL}}, u_{*}, Z_{i}$, and $w_{*}$ & 84 & 74 & 72 & 77 & 32 \\
\hline MDA5 & $U_{\mathrm{CBL}}, u_{*}, Z_{i}, w_{*}$, and $-L$ & 82 & 74 & 68 & 75 & 37 \\
\hline MDA6 & $U_{\mathrm{CBL}}, u_{*}, Z_{i}, w_{*},-L$, and $d U / d z$ & 82 & 76 & 68 & 75 & 33 \\
\hline MDA7 & All variables & 80 & 76 & 62 & 73 & 42 \\
\hline
\end{tabular}

The value of additional predictors for discriminant analysis is explored by providing every potential variable combination from three variables to seven variables to the MDA, yielding 99 unique combinations. Results using the training data show that the mean percent correct initially increases on average as the number of variables used by MDA increases (Fig. 7), reaching a maximum of $77 \%$ mean percent correct for the four-variable MDA (Table 3). The predictors selected for the best-performing MDAs are consistent, such that the predictors for the three-variable MDA appear in the four-, five-, and six-variable MDAs, as expected. The four most important variables are $U_{\mathrm{CBL}}, u_{*}, Z_{i}$, and $w_{*}$ (Table 3 ), representing wind shear, buoyancy and CBL geometry. While $U_{\mathrm{CBL}}$ and $u_{*}$ have a correlation of 0.66 (Table 2), the correlations among all other variable pairs in this 4-variable group are less than 0.35 . These results further strengthen the conclusions from earlier studies that $U_{\mathrm{CBL}}$ is an important variable for determining CBL circulation type. The importance of the variables $Z_{i}, u_{*}$, and $w_{*}$ further underscores the interplay between wind shear and buoyancy in determining circulation type.

The best-performing variable combinations in MDA change when assessed using the independent dataset. The MDA function coefficients for all 21 two-variable combinations are as determined from the training data, but the independent observations are provided as input and the group classification is the only output. Using the independent data, the combination of $Z_{i}$ and SHF yields a 75\% correct for nulls (not shown), although as seen with the training data this combination has little ability to distinguish HCRs or cells. Results indicate that the best two-variable MDA combination is $u_{*}$ and SHF, which yields a weighted mean percent correct of $72 \%$ (last column in Table 3) when the observed frequencies are taken into account, slightly better than the weighted mean percent correct of $69 \%$ found using a simple threshold value for $U_{\mathrm{CBL}}$. However, more predictors may further improve the discrimination between the three groups using MDA.

As done with the two-variable MDA, the function coefficients for the three to seven variable MDA combinations are as determined from the training data, but the independent observations are provided as input and the group classification is the only output. Results show that when the MDA models developed on the training dataset are applied to the independent data the mean percent correct decreases by $21 \%$ on average, as expected (Fig. 7). Yet the mean percent correct for individual MDA models consistently remains $\geq 33 \%$ (Fig. 7), the percentage that results from a random assignment to regime in a three category MDA. Results suggest that the MDA using from three to seven variables performs similar to or worse than was found using two variables when given the independent testing data and evaluated using the weighted mean percent correct, indicating that the additional observations are not helpful and including more variables in MDA may cause 


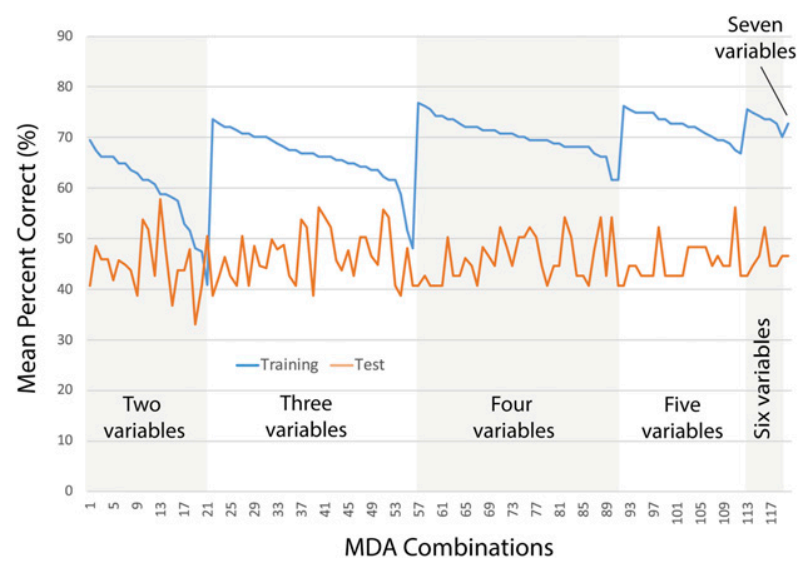

FIG. 7. Mean percent correct calculated from the three groups (HCR, cells, and nulls) plotted vs the 120 unique variable combinations used in MDA and ordered by the number of variables given to MDA, starting at two variables on the left and ending with all seven variables on the right. The blue line is the mean percent correct determined using the training data, whereas the orange line is mean percent correct using the 50 independent test cases.

overfitting. The best overall MDA as determined from the independent dataset uses only two variables, $u_{*}$ and SHF, followed by the three-variable MDA using $u_{*}, \mathrm{SHF}$, and $L$; both have a weighted mean percent correct of $72 \%$. This result suggests that it is possible to predict CBL circulation type using surface data alone using MDA.

\section{Summary}

Surface observations from the Oklahoma Mesonet and CBL observations from the KTLX WSR-88D are used to calculate $\mathrm{SHF}, L, u_{*}, U_{\mathrm{CBL}}, d U / d z, Z_{i}$, and $w_{*}$ for 50 cases each of HCR, cell and null events in central Oklahoma between 2013 and 2017. These environmental variables can be estimated routinely at many locations. The size of the dataset yields enough variability to examine which environmental parameters are associated with the three circulation types, with cases selected from the dataset of Banghoff et al. (2020). The 150 cases represent the largest dataset to date to determine whether environmental conditions can be used to predict $\mathrm{CBL}$ circulation type-HCR, cell, or null. Results from the training data indicate that MDA applied to observations of $U_{\mathrm{CBL}}, u_{*}, Z_{i}$, and $w_{*}$ yields a $77 \%$ mean percent correct and an $80 \%$ weighted mean percent correct. When MDA is applied to an independent dataset, the largest weighted mean percent correct drops to $72 \%$ and the best-performing MDA is a two-variable model using $u_{*}$ and SHF, which highlights the importance of winds and buoyancy in determining circulation type. This result further suggests that surface observations alone may be helpful in predicting CBL circulation type. The presence of hybrid events in the datasets, such as combined HCR and cell circulations, would adversely affect the MDA results and may contribute to a lower weighted mean percent correct.

If one is interested only in whether the CBL circulation on a given day is likely to be a cell or $\mathrm{HCR}$, then $U_{\mathrm{CBL}}=6 \mathrm{~m} \mathrm{~s}^{-1}$ can be used to discriminate between the two, with HCRs present $76 \%$ of the time in the independent dataset when $U_{\mathrm{CBL}}>6 \mathrm{~m} \mathrm{~s}^{-1}$ and cells present $71 \%$ of the time when this mean wind speed value is not exceeded. This yields a weighted mean percent correct of $69 \%$ when taking into account the observed frequencies of the CBL circulations, just slightly less than found using MDA. This wind speed threshold agrees well with previous values of $7 \mathrm{~m} \mathrm{~s}^{-1}$ suggested by Woodcock (1940), $5 \mathrm{~m} \mathrm{~s}^{-1}$ suggested by Christian and Wakimoto (1989), and $5.5 \mathrm{~m} \mathrm{~s}^{-1}$ suggested by Weckwerth et al. (1997).

As mentioned previously, it is the ability to determine null events that is most difficult. Because Banghoff et al. (2020) show that HCRs or cells occur on $92 \%$ of the days without precipitation, the importance of predicting null events may not be large. Yet, the reason why null events occur when conditions seem favorable for the development of boundary layer circulations, such as HCRs and cells, is unclear. The MDA results are encouraging in that they suggest that the environments of null events can be distinguished from those of cells and HCRs and deserves further study. The results of this study further show that advent of operational dual-polarization WSR-88Ds across the United States opens a new research opportunity for studying boundary layer circulations using radar. A simple combination of operational radars with a well-designed surface observation network has shown itself to be very fruitful, which can benefit other areas of boundary layer research.

Acknowledgments. Funding for this work is provided by NSF Award AGS-1632850. Special thanks are given to members of the Research in Applications of Dual-Polarization and Advanced Radar (RADAR) research group at The Pennsylvania State University (PSU) for sharing code and providing insightful suggestions. We greatly appreciate the constructive and helpful comments of Dr. Margaret LeMone and an anonymous reviewer. This work is part of the first author's M.S. thesis at PSU.

Data availability statement. The 10 -year warm-season climatology of HCRs, cells, and nulls is openly available on the PSU Data Commons (https://doi.org/10.26208/9d63-5p83) as cited in Stensrud et al. (2019). WSR-88D observations are freely available from the National Centers for Environmental Information. Oklahoma Mesonet observations are available from the Oklahoma Climatological Survey.

\section{REFERENCES}

Angell, J. K., D. H. Pack, and C. R. Dickson, 1968: A Lagrangian study of helical circulations in the planetary boundary layer. J. Atmos. Sci., 25, 707-717, https://doi.org/10.1175/15200469(1968)025<0707:ALSOHC>2.0.CO;2.

Asai, T., 1970: Stability of a plane parallel flow with variable vertical shear and unstable stratification. J. Meteor. Soc. Japan, 48, 129-139, https://doi.org/10.2151/jmsj1965.48.2_129.

Atkinson, B. W., and J. W. Zhang, 1996: Mesoscale shallow convection in the atmosphere. Rev. Geophys., 34, 403-431, https:// doi.org/10.1029/96RG02623.

Banghoff, J. R., D. J. Stensrud, and M. R. Kumjian, 2018: Convective boundary layer depth estimation from S-band 
dual-polarization radar. J. Atmos. Oceanic Technol., 35, 1723-1733, https://doi.org/10.1175/JTECH-D-17-0210.1.

_ J. D. Sorber, D. J. Stensrud, G. S. Young, and M. R. Kumjian, 2020: A 10-year warm-season climatology of horizontal convective rolls and cellular convection in Central Oklahoma. Mon. Wea. Rev., 148, 21-42, https://doi.org/10.1175/MWR-D19-0136.1.

Berger, M., and R. Doviak, 1978: Dual Doppler radar observations of wind fields in a dry convective boundary layer. Fourth Symp. on Meteorological Observations and Instrumentation, Denver, CO, Amer. Meteor. Soc., 219-226.

Brock, F. V., K. C. Crawford, R. L. Elliott, G. W. Cuperus, S. J. Stadler, H. L. Johnson, and M. D. Eilts, 1995: The Oklahoma Mesonet: A technical overview. J. Atmos. Oceanic Technol., 12, 5-19, https://doi.org/10.1175/1520-0426(1995)012<0005: TOMATO $>2.0 . \mathrm{CO} ; 2$.

Brotzge, J. A., and K. C. Crawford, 2000: Estimating sensible heat flux from the Oklahoma Mesonet. J. Appl. Meteor., 39, 102-116, https://doi.org/10.1175/1520-0450(2000)039<0102:ESHFFT> 2.0.CO;2.

Brown, R. A., 1980: Longitudinal instabilities and secondary flows in the planetary boundary layer: A review. Rev. Geophys. Space Phys., 18, 683-697, https://doi.org/10.1029/RG018i003p00683.

Browning, K. A., and R. Wexler, 1968: The determination of kinematic properties of a wind field using Doppler radar. J. Appl. Meteor., 7, 105-113, https://doi.org/10.1175/1520-0450(1968) 007<0105:TDOKPO $>2$.0.CO;2.

Brümmer, B., 1999: Roll and cell convection in wintertime Arctic cold-air outbreaks. J. Atmos. Sci., 56, 2613-2636, https://doi.org/ 10.1175/1520-0469(1999)056<2613:RACCIW>2.0.CO;2.

—, S. Bakan, and H. Hinzpeter, 1985: Kontur: Observations of cloud streets and open cellular structures. Dyn. Atmos. Oceans, 9, 281-296, https://doi.org/10.1016/0377-0265(85)90024-7.

Christian, T. W., and R. M. Wakimoto, 1989: The relationship between radar reflectivities and clouds associated with horizontal roll convection on 8 August 1982. Mon. Wea. Rev., 117, 1530-1544, https://doi.org/10.1175/1520-0493(1989)117<1530: TRBRRA $>2.0 . \mathrm{CO} ; 2$.

Davison, J. L., R. M. Rauber, L. Di Girolamo, and M. A. LeMone, 2013: A revised conceptual model of the tropical marine boundary layer. Part III: Bragg scattering layer statistical properties. J. Atmos. Sci., 70, 3047-3062, https://doi.org/ 10.1175/JAS-D-12-0323.1.

Deardorff, J. W., 1976: Discussion of 'thermals over the sea and gull flight behavior' by A. H. Woodcock. Bound.-Layer Meteor., 10, 241-246, https://doi.org/10.1007/BF00229293.

Fisher, R. A., 1936: The use of multiple measurements in taxonomic problems. Ann. Eugen., 7, 179-188, https://doi.org/ 10.1111/j.1469-1809.1936.tb02137.x.

Geerts, B., and Q. Miao, 2005: A simple numerical model of the flight behavior of small insects in the atmospheric convective boundary layer. Environ. Entomol., 34, 353-360, https://doi.org/ 10.1603/0046-225X-34.2.353.

Grossman, R. L., 1982: An analysis of vertical-velocity spectra obtained in the BOMEX fair-weather trade-wind boundary layer. Bound.-Layer Meteor., 23, 323-357, https://doi.org/ 10.1007/BF00121120.

Kelly, R. D., 1982: A single Doppler radar study of horizontal-roll convection in a lake-effect snow storm. J. Atmos. Sci., 39, 1521-1531, https://doi.org/10.1175/1520-0469(1982)039<1521: ASDRSO $>2.0 . \mathrm{CO} ; 2$.

Konrad, T. G., 1970: The dynamics of the convective process in clear air as seen by radar. J. Atmos. Sci., 27, 1138-1147,
https://doi.org/10.1175/1520-0469(1970)027<1138:TDOTCP > 2.0.CO;2.

Kristovich, D. A. R., 1993: Mean circulations of boundary-layer rolls in lake-effect snow storms. Bound.-Layer Meteor., 63, 293-315, https://doi.org/10.1007/BF00710463.

Kuettner, J., 1959: The band structure of the atmosphere. Tellus, 11, 267-294, https://doi.org/10.3402/tellusa.v11i3.9319.

, 1971: Cloud bands in the Earth's atmosphere: Observations and theory. Tellus, 23, 404-426, https://doi.org/10.3402/ tellusa.v23i4-5.10519.

Kumjian, M. R., A. V. Ryzhkov, H. D. Reeves, and T. J. Schuur, 2013: A dual-polarization radar signature of hydrometeor refreezing in winter storms. J. Appl. Meteor. Climatol., 52, 25492566, https://doi.org/10.1175/JAMC-D-12-0311.1.

LeMone, M. A., 1973: The structure and dynamics of horizontal roll vortices in the planetary boundary layer. J. Atmos. Sci., 30, 1077-1091, https://doi.org/10.1175/1520-0469(1973)030<1077: TSADOH $>2.0 . \mathrm{CO} ; 2$.

—, F. Chen, M. Tewari, J. Dudhia, B. Geerts, Q. Miao, R. L. Coulter, and R. L. Grossman, 2010: Simulating the IHOP_2002 fair-weather CBL with the WRF-ARW-Noah modeling system. Part II: Structures from a few kilometers to $100 \mathrm{~km}$ across. Mon. Wea. Rev., 138, 745-764, https://doi.org/10.1175/ 2009MWR3004.1.

Mahmood, R., and Coauthors, 2017: Mesonets: Mesoscale weather and climate observations for the United States. Bull. Amer. Meteor. Soc., 98, 1349-1361, https://doi.org/10.1175/BAMS-D15-00258.1.

Malkus, J. S., and H. Riehl, 1964: Cloud structure and distributions over the tropical Pacific Ocean. Quart. J. Roy. Meteor. Soc., 91, 275-287, https://doi.org/10.1111/J.2153-3490.1964.TB00167.X.

McPherson, R. A., and Coauthors, 2007: Statewide monitoring of the mesoscale environment: A technical update on the Oklahoma Mesonet. J. Atmos. Oceanic Technol., 24, 301-321, https://doi.org/10.1175/JTECH1976.1.

Melnikov, V. M., R. J. Doviak, D. S. Zrnić, and D. J. Stensrud, 2011: Mapping Bragg scatter with a polarimetric WSR-88D. J. Atmos. Oceanic Technol., 28, 1273-1285, https://doi.org/ 10.1175/JTECH-D-10-05048.1.

,,$-- \ldots$, and,- 2013 : Structures of Bragg scatter observed with the polarimetric WSR-88D. J. Atmos. Oceanic Technol., 30, 1253-1258, https://doi.org/10.1175/JTECH-D12-00210.1.

Panofsky, H. A., 1963: Determination of stress from wind and temperature measurements. Quart. J. Roy. Meteor. Soc., 89, 85-94, https://doi.org/10.1002/qj.49708937906.

Paulson, C. A., 1970: The mathematical representation of wind speed and temperature profiles in the unstable atmospheric surface layer. J. Appl. Meteor., 9, 857-861, https://doi.org/ 10.1175/1520-0450(1970)009<0857:TMROWS>2.0.CO;2.

Rao, C. R., 1948: The utilization of multiple measurements in problems of biological classification. J. Roy. Stat. Soc., 10B, 159-193, https://doi.org/10.1111/j.2517-6161.1948.tb00008.x.

Richardson, L. M., J. G. Cunningham, W. D. Zittel, R. R. Lee, R. L. Ice, V. M. Melnikov, N. P. Hoban, and J. G. Gebauer, 2017a: Bragg scatter detection by the WSR-88D. Part I: Algorithm development. J. Atmos. Oceanic Technol., 34, 465-478, https:// doi.org/10.1175/JTECH-D-16-0030.1.

—_, W. D. Zittel, R. R. Lee, V. M. Melnikov, R. L. Ice, and J. G. Cunningham, 2017b: Bragg scatter detection by the WSR-88D. Part II: Assessment of $Z_{\mathrm{DR}}$ bias estimation. J. Atmos. Oceanic Technol., 34, 479-493, https://doi.org/10.1175/ JTECH-D-16-0031.1. 
Ryzhkov, A., P. Zhang, H. Reeves, M. Kumjian, T. Tschallener, S. Trömel, and C. Simmer, 2016: Quasi-vertical profiles-A new way to look at polarimetric radar data. J. Atmos. Oceanic Technol., 33, 551-562, https://doi.org/10.1175/JTECH-D-150020.1.

Stensrud, D. J., M. R. Kumjian, J. R. Banghoff, and J. D. Sorber, 2019: 10-year warm-season Doppler radar climatology of horizontal convective rolls and cellular convection in central Oklahoma. The Pennsylvania State University Data Commons, accessed 29 May 2020, https://doi.org/10.26208/ 9d63-5p83.

Stull, R. B., 1988: An Introduction to Boundary Layer Meteorology. Kluwer Academic, 666 pp.

Viana, D. R., and C. A. Sansigolo, 2016: Monthly and seasonal rainfall forecasting in southern Brazil using multiple discriminant analysis. Wea. Forecasting, 31, 1947-1960, https://doi.org/ 10.1175/WAF-D-15-0155.1.

Weckwerth, T. M., and D. B. Parsons, 2006: A review of convection initiation and motivation for IHOP_2002. Mon. Wea. Rev., 134, 5-22, https://doi.org/10.1175/MWR3067.1.

_ J. W. Wilson, and R. M. Wakimoto, 1996: Thermodynamic variability within the convective boundary layer due to horizontal convective rolls. Mon. Wea. Rev., 124, 769-784,
https://doi.org/10.1175/1520-0493(1996)124<0769:TVWTCB > 2.0.CO;2.

,,$---\longrightarrow$, and N. A. Crook, 1997: Horizontal convective rolls: Determining the environmental conditions supporting their existence and characteristics. Mon. Wea. Rev., 125, 505-526, https://doi.org/10.1175/1520-0493(1997)125<0505: HCRDTE $>2.0 . \mathrm{CO} ; 2$.

Wilks, D. S., 2006: Statistical Methods in the Atmospheric Sciences. 2nd ed. International Geophysics Series, Vol. 100, Academic Press, 648 pp.

Wilson, J. W., G. B. Foote, N. A. Crook, J. C. Fankhauser, C. G. Wade, J. D. Tuttle, C. K. Mueller, and S. K. Krueger, 1992: The role of boundary-layer convergence zones and horizontal rolls in the initiation of thunderstorms: A case study. Mon. Wea. Rev., 120, 1785-1815, https://doi.org/10.1175/15200493(1992) $120<1785$ :TROBLC $>2.0$. CO;2.

Woodcock, A. H., 1940: Convection and soaring over the open sea. J. Mar. Res., 3, 248-253.

Xue, M., and W. J. Martin, 2006: A high-resolution modeling study of the 24 May 2002 dryline case during IHOP. Part I: Numerical simulation and general evolution of the dryline and convection. Mon. Wea. Rev., 134, 149-171, https://doi.org/ 10.1175/MWR3071.1. 